\title{
Auditors' issue contingency of reduced audit quality acts: perceptions of managers and partners
}

\author{
Mid Sweden University, \\ SE-851 70 Sundsvall, Sweden \\ Email: Jan.Svanberg@miun.se \\ Email: Peter.Ohman@miun.se \\ *Corresponding author
}

Jan Svanberg* and Peter Öhman

Department of Business, Economics and Law,

Centre for Research on Economic Relations,

\begin{abstract}
This study examines how managers and partners in audit firms perceive the moral intensity of various reduced audit quality (RAQ) acts, and whether perceived moral intensity affects the likelihood of these acts being committed. We surveyed managers and partners employed by audit firms operating in Sweden, measuring their perceptions of the moral intensity of seven RAQ acts using Jones' (1991) moral intensity scale and their self-reported frequencies of these acts. The study finds that managers and partners regard RAQ acts as morally serious, and that the moral intensity of an RAQ act is negatively related to the frequency of the act's occurrence for three of the seven acts. This suggests that managers' and partners' moral intensity perceptions do not unequivocally discourage auditors from committing these offences.
\end{abstract}

Keywords: auditing; reduced audit quality acts; RAQ; moral intensity; moral issues; ethical judgments.

Reference to this paper should be made as follows: Svanberg, J. and Öhman, P. (2019) 'Auditors' issue contingency of reduced audit quality acts: perceptions of managers and partners', Int. J. Accounting, Auditing and Performance Evaluation, Vol. 15, No. 1, pp.57-88.

Biographical notes: Jan Svanberg is an Assistant Professor $(\mathrm{PhD})$ of Business Administration at Centre for Research on Economic Relations (CER) at Mid Sweden University. His research interests are behavioural issues in accounting and auditing.

Peter Öhman is a Professor $(\mathrm{PhD})$ of Business Administration at Centre for Research on Economic Relations (CER) at Mid Sweden University. His research interests are primary in accounting, auditing and banking. 


\section{Introduction}

Previous research has examined the extent of reduced audit quality (RAQ) acts, and the overall finding is that such acts occur in all countries surveyed. Studies of the prevalence of RAQ acts in the USA (Rhode, 1978; Alderman and Deitrick, 1982; Kelley and Margheim, 1990; Malone and Roberts, 1996; Donnelly et al., 2003), the UK (Willett and Page, 1996; Lee, 2002), Ireland (Otley and Pierce, 1996a, 1996b; Pierce and Sweeney, 2004), and, more recently, in Sweden (Svanberg and Öhman, 2013, 2016) provide a relatively clear picture of the extent of RAQ acts.

At the core of the issue is the auditor's public role. Because users of financial statements are reliant on unbiased auditor judgment, auditor ethics should be crucial to auditing (Shaub and Braun, 2014) and strong ethical attitudes should reduce the incidence of RAQ acts (Sweeney et al., 2010). Yet the practice of RAQ acts seems inconsistent with this. Low-ranking auditors, i.e., junior and senior auditors, who seem to suffer the most from time budget pressure (TBP) (cf. Kelley and Margheim, 1990), perceive RAQ acts as unethical, but regard these behaviours as having few consequences for themselves because perpetrators are difficult to identify (Coram et al., 2008). Because it is practically impossible for managers to supervise everything their subordinates do, RAQ acts can be concealed. Related evidence suggests that high-ranking auditors, i.e., managers and partners, are aware of, but do not talk about, RAQ acts (Alderman and Deitrick, 1982; McNair, 1991; Otley and Pierce, 1996b; Pierce and Sweeney, 2005, 2006).

Although Coram et al. (2008) and Sweeney et al. (2013) have studied the moral intensities of RAQ acts as perceived by low-ranking auditors, no available study has examined how high-ranking auditors, i.e., managers and partners, ethically view RAQ acts. Managers' and partners' perceptions of the moral intensities of RAQ acts are likely to influence how junior and senior auditors behave, because auditors who commit such acts tend to perceive that their audit firm turns a blind eye to irregular auditing and these auditors believe that their peers act in the same way (Willett and Page, 1996).

That the 'tone at the top' may be permissive is evidenced by the finding that $27 \%$ of British auditors perceived that their firms did in practice tacitly countenance shortcuts [Willett and Page, (1996), p.114]. Furthermore, partners have a greater tendency than do junior or senior auditors to underestimate the frequency of RAQ acts, particularly those that could be potentially damaging, such as premature sign-off (Willett and Page, 1996; Pierce and Sweeney, 2005). In the same vein, Pierce and Sweeney (2005) report that some high-ranking auditors claim that RAQ acts do not threaten audit quality because they occur in non-critical audit steps and that audit staff overestimate the frequency of RAQ acts. Managers and partners believe that detecting RAQ acts incurs few and relatively unimportant consequences for audit staff and the audit firm. If this dissimilarity between low- and high-ranking auditors' perceptions is anything but an unhappy coincidence, it justifies examination of the moral intensity perceptions of managers and partners. Owing to these indications of differences between low- and high-ranking auditors, managers and partners may have different moral intensity judgments of RAQ acts from those of the low-ranking auditors examined by Coram et al. (2008) and Sweeney et al. (2013). 
The present study is informed by the issue-contingent model of moral decision-making (Jones, 1991). The model suggests that situations differ in moral intensity and that moral intensity affects how certain aspects of situations are perceived and used as premises for moral decision-making. As indicated, we examine the moral intensity of RAQ acts as perceived by managers and partners, and consider whether various acts are perceived as differing in moral intensity. Moreover, as the model claims that moral intensity predicts the likelihood of ethical behaviour, we expand on the previous work of Coram et al. (2008) and Sweeney et al. (2013) by also examining the relationship between the perceived moral intensity of RAQ acts and their self-reported occurrence. This is of interest because moral intensity may affect the likelihood that auditors will commit these acts. Ideally, auditors are deterred from RAQ acts perceived as strongly immoral.

Considering the lack of research into the impact of the perceived moral intensity of RAQ acts on their likelihood of being committed (cf. Cohen and Bennie, 2006; McMahon and Harvey, 2007), we provide direct intra-subject evidence of the extent to which managers and partners perceive the ethical intensity of various RAQ acts and of the relationship between moral intensity and the likelihood of these acts. We focus on seven acts to facilitate a broad comparison of the moral intensity of RAQ acts examined in previous research. One hundred and thirty-six managers and partners in audit firms in Sweden completed a questionnaire designed to examine whether these seven acts differ in perceived moral intensity and whether the intensities predict the frequencies of such acts.

Our examination of how managers and partners perceive the moral intensity of RAQ acts contributes to the accounting literature because prior evidence suggests that high- and low-ranking auditors may perceive RAQ acts in different ways (Willett and Page, 1996; Pierce and Sweeney, 2005). We also contribute to the accounting literature by examining the relationship between managers' and partners' perceptions of the moral intensity of individual RAQ acts and the frequencies of these acts, in contrast to Sweeney et al. (2013), who examined this relationship for inexperienced auditors. Managers and partners involved in fieldwork may commit RAQ acts, and the link between perceived moral intensity and behaviour signals managers' and partners' permissiveness regarding RAQ acts because they act not only as auditors but also as role models to low-ranking auditors. Furthermore, while Sweeney et al. (2013) examined the impact of RAQ acts' moral intensity on intentions to act, we focus on the impact on actual behaviour.

The remainder of the paper is structured as follows: the next section, in which we review the literature, is followed by a presentation of the hypotheses. We then outline the research method. This is followed by a presentation of the results, after which we conclude the paper by discussing its research implications.

\section{Literature review}

\subsection{Ethical perceptions of RAQ acts}

Previous studies have reported relatively high levels of RAQ acts committed by audit staff (Rhode, 1978; Alderman and Deitrick, 1982; Otley and Pierce, 1996a, 1996b; Pierce and Sweeney, 2006), and it was recently suggested that even managers and partners may perform RAQ acts to some extent (Svanberg and Öhman, 2013). Previous research has also examined whether audit firm control systems affect the frequencies of RAQ acts and 
found that low-ranking auditors often face pressure from tight time budgets (Lee, 2002; Pierce and Sweeney, 2004), causing harm to auditors (Cooper et al., 2001) and to stakeholders and society (Bazerman et al., 2002). Audit firms emphasise meeting time budgets as a measure of efficiency (Pierce and Sweeney, 2004), and unpaid overtime to cover for unattained time budgets is suggested to be an informal cultural norm in some audit firms (Sweeney and Pierce, 2006). Other examined factors are personality variables (Malone and Roberts, 1996), firm size (Margheim and Pany, 1986), and organisational commitment and leadership (Otley and Pierce, 1996a).

Given their potential to undermine the reliability of fieldwork, one could expect audit firms to emphasise preventing RAQ acts and to entertain the notion that audit quality may be damaged by them. However, as described in the Introduction, this is not the case. Pierce and Sweeney $(2005,2006)$ reported that managers and partners in audit firms do not consider RAQ acts as having serious consequences for the auditors, the audit firm, or the community. This suggests that RAQ act prevention must rely on individual ethical judgments (Kaplan, 1995), and that the audit firm could encourage restrictive ethical judgments by enforcing a strong ethical culture (Svanberg and Öhman, 2013). Whether auditors' ethical perceptions of RAQ acts actually discourage them from committing these acts is an open question. The research of Pierce and Sweeney $(2005,2006)$ leans towards 'no'. However, Coram et al.'s (2008) work says 'yes', and the only empirical study on the link between the perceived moral intensity of RAQ acts and the likelihood of committing them, by Sweeney et al. (2013), found evidence of a negative relationship between perceived ethical intensity and ethical decision-making regarding three RAQ acts.

Related to the findings of Sweeney et al. (2013), previous research identifies at least three indications that ethical evaluations of various RAQ acts affect their probability of being committed. First, previous studies have examined the incidence of individual RAQ acts, revealing that their frequencies differ. Willett and Page (1996) found that auditors had a greater tendency to reject an awkward-looking item from a sample than not to test all items in a reported sample, and that they were least likely to accept doubtful audit evidence. Further evidence that various RAQ acts differ in their likelihood of occurring was provided by Malone and Roberts (1996), who found that $75 \%$ of the studied auditors indicated that they never committed false sign-off, 58\% never failed to research a technical issue, and 52\% never superficially reviewed supporting documents. Moreover, $50 \%$ never failed to pursue questionable items, $42 \%$ never accepted weak client explanations, and $26 \%$ never did less work than normal. Otley and Pierce (1996b) examined four RAQ acts and found that superficial review of client documents was the most frequent and failure to research an accounting principle the least frequent act. The same authors examined five RAQ acts (Otley and Pierce, 1996a), and again found that superficial review of client documents was the most frequent, while false sign-off was the least frequent. The fact that RAQ acts occur at different frequencies or likelihoods does not, however, constitute evidence that the perceived moral intensities of the acts cause, or are even associated with, the variation. The RAQ acts' frequencies may vary for any reason.

Second, while RAQ acts have frequently been examined as a composite variable, with the tacit assumption that RAQ acts are homogeneous behaviours, differences in their frequencies suggest that various acts differ in important ways. Herrbach (2001) observed such differences, finding that the composite measure of six RAQ acts was not coherent, and that the measure consisted of at least two components, false sign-off being distinct 
from the other acts. Further support for the idea that different RAQ acts have different attributes was provided by Coram et al. (2004), who found that TBP interacts with risk of misstatement for only one of two RAQ acts under study, suggesting that auditors may perceive differences in the acts themselves. However, although this evidence is important in itself, it does not constitute evidence of a link between the moral intensities of individual RAQ acts and their likelihood of occurring.

Third, Coram et al. (2008) found that the frequencies of RAQ acts identified in previous studies were inversely related to auditors' assessments of these acts' ethical intensities. The surveyed auditors perceived various RAQ acts as differing in moral intensity. Earlier studies reported that the acts deemed more ethically serious and more likely to have material effects were committed more rarely, while those considered less ethically serious and less likely to have effects were committed more often. These facts suggest, but do not establish, that perceived ethical intensity affects the likelihood that an auditor will commit an RAQ act. According to Jones (1991), the higher the moral intensity of an issue, the less likely an individual will engage in unethical behaviour related to it. Providing evidence of this link requires an intra-subject examination of auditors' perceptions of the moral intensities of individual RAQ acts and of how frequently auditors commit each type of act.

\subsection{Moral intensity}

Pierce and Sweeney $(2005,2006)$ examined the perceptions of 12 partners and 25 senior auditors regarding the effects of individual RAQ acts on auditors, audit firms, the audit profession, and the wider business community. They used interviews and asked about the effects on audit quality of RAQ acts, but did not adopt any measurement scale, such as Jones' (1991) moral intensity scale. Instead, they discussed previous research findings with auditors to examine whether auditors were aware of the pressure-induced behaviours reported in research. The lack of a theoretically based measure of moral intensity in these studies limits the interpretation of the results. Coram et al. (2008) examined the ethical perceptions of 42 junior auditors using Jones' (1999) theoretically derived definition of moral intensity and found that moral intensity differs between individual RAQ acts. By comparing the moral intensities with previous findings regarding how often the RAQ acts are committed, Coram et al. (2008) also found that those acts regarded as more severe appear to be less frequent. Sweeney et al. (2013) examined the mediating role of perceived ethical intensity in the relationship between the perceived ethical culture of an audit firm and auditors' intentions to engage in premature sign-off, over-reliance on client work, and biased sample selection. By examining 463 Irish and 117 US auditors with limited audit experience, the authors found a direct relationship between perceived ethical intensity and ethical decision-making regarding RAQ acts. However, they failed to demonstrate a negative relationship between the auditors' ethical evaluations of the RAQ acts and their intentions to engage in those behaviours.

Although Sweeney et al. (2013) appear to have found that ethical intensity prevents inexperienced auditors from conducting RAQ acts, the finding is not of a relationship between actually committed RAQ acts and moral intensity, but only between intentions to commit RAQ acts and moral intensity. This distinction is important because intention to act represents a mental state, and there is uncertainty about the extent to which the intention translates into an actual act (Rest, 1986). Intention to act refers to a hypothetical 
situation that cannot possibly capture all the behavioural cues a real situation may have and does not realistically represent the many circumstances that could trigger real behaviour. Recent research demonstrates that the presence of reminders of professional identity substantially strengthens auditor objectivity by means of psychological priming (Bauer, 2015). According to that study, the effect of priming is rapid and may dramatically change how auditors choose to act in a situation. That type of effect makes it likely that actual behaviour will differ from intentions in many cases. Seen in this light, the evidence presented by Sweeney et al. (2013) is inconclusive because differences between intended and actual behaviour are caused by hypothetical bias (Campbell, 1963), i.e., the difference between a symbolic representation and a real-life situation (Blumer, 1955).

The moral intensity construct was defined by Jones (1991, p.372) as 'a construct that captures the extent of issue-related moral imperative in a situation'. Moral intensity varies from issue to issue, and Jones (1991) claimed that the higher the moral intensity of an act, the less likely a person is to commit it. Moral intensity triggers awareness of the situation's moral dimensions, with the effect that moral decision premises tend to be more relevant when moral intensity is high. Research into business ethics and accounting (e.g., Sweeney and Costello, 2009; Taylor and Curtis, 2013) has adopted the moral intensity construct and evidence indicates that moral intensity affects the likelihood of immoral behaviour.

Jones (1991) defined six dimensions of moral intensity as follows: social consensus is the degree of social agreement that a proposed act is evil (or good), meaning that people turn to others for guidance on its degree of social acceptability. Any ambiguity regarding the ethically correct course of action is reduced when a high degree of social consensus exists. Magnitude of consequences is the sum of the harms (or benefits) to the victims (or beneficiaries) of the moral act in question, more serious consequences evoking stronger moral reactions. These two dimensions appear to have the most influence on the ethical decision-making process (Carlson et al., 2002; Barnett and Valentine, 2004; McMahon and Harvey, 2007). The third factor, probability of effect, is defined as a function of the joint probability that an act will actually occur and that the act will actually cause harm. Temporal immediacy is defined as the time elapsed between the commission of the moral act and the onset of its consequences. Concentration of effect is conceived as an inverse function of the number of people affected by an act of given magnitude and, finally, proximity is defined as the sense of nearness (i.e., social, cultural, psychological, and physical) between the moral agent and the victims (beneficiaries) of an evil (beneficial) act.

We are interested in how managers and partners perceive the individual moral intensity dimensions of each of seven of the RAQ acts introduced in the literature review section. Differences between RAQ acts on any of the moral intensity dimensions can suggest interpretations of why auditors tend to commit these acts. Some dimensions may provide a stronger incentive to avoid a specific act than do other dimensions. We focus on differences between RAQ acts using total moral intensity as well as individual dimensions of moral intensity (as described below). 


\section{Research hypotheses}

\subsection{Moral intensity dimensions used in the study}

RAQ acts can be expected to vary across the identified dimensions of moral intensity. We examine moral intensity levels and the differences between RAQ acts using three of these moral intensity dimensions - i.e., social consensus, magnitude of consequences, and probability of effect - that may vary between RAQ acts. The reasons for this proposed variation are explained below. Related to this, note that there is no previous evidence in the accounting literature that managers' and partners' perceptions of the moral intensity of individual RAQ acts differ between the acts. Providing such evidence is important because Jones' (1991) model predicts that the level of moral intensity of an act is related to the likelihood of the act's occurrence.

The probability of effect dimension has two measures: one for auditors, measuring the likelihood that an effect will affect the auditor who commits the RAQ act, and one for financial statement users, measuring the likelihood that the act will allow a material misstatement to appear in the client's financial reports. The magnitude of effect dimension for auditors has no such corresponding measure for financial statement users, because the magnitude of effects for financial statement users is determined by the size and nature of the material misstatement of the client's financial reports, which does not vary between RAQ acts. The social consensus dimension is related to auditors.

The other dimensions of moral intensity mentioned in the literature review section are excluded from this analysis because, per definition, there can be no difference in moral intensity between the acts. For example, concentration of effect cannot vary between RAQ acts because the effect of the acts is ultimately a misstatement of client accounting and this effect is the same for all RAQ acts.

\subsection{Social consensus among auditors}

A high degree of agreement that an act is or is not ethical is more likely if a situation involves clear violation of professional or legal standards. According to Jones (1991), it is more difficult for a person to act ethically if the person does not know what ethical standards prescribe in a given situation. Legal prohibition or the availability of accounting or auditing standards that regulate an issue therefore increases the obviousness that certain behaviours are appropriate while making unethical behaviour appear more blameworthy. Some variation between individual RAQ acts is likely to be found on this dimension. While false sign-off violates auditing standards, accepting weak explanations from a client and failing to research a technical issue are in a grey area (Malone and Roberts, 1996; Otley and Pierce, 1996a; Herrbach, 2001).

When we apply the social consensus dimension to RAQ acts, we expect to find variation between them partly because auditing standards provide varying degrees of guidance regarding RAQ acts and partly because of peer influence and the influence of authorities (Coram et al., 2008; Sweeney et al., 2013). We accordingly propose the following hypothesis:

H1 The perceived social consensus among auditors that an RAQ act is wrong varies across RAQ acts. 


\subsection{Magnitude of consequences for auditors}

The magnitude of consequences often concerns the consequences for others affected by an unethical act, worse consequences implying higher moral intensity. However, it is possible to define magnitude of consequences from the auditor's perspective, following the approach of Coram et al. (2008). The consequences for the auditors themselves are the penalties incurred after the wrongdoing has been detected, and we expect auditors to perceive proportionality between the type of fault and the severity of punishment. In line with Sweeney et al. (2013), we expect to find that auditors perceive the severity of punishment as varying among RAQ acts. We accordingly formulate the following hypothesis:

$\mathrm{H} 2$ The perceived magnitude of consequences for auditors varies across RAQ acts.

\subsection{Probability of effect on financial statement users and auditors}

Provided that an RAQ act has been committed, the probability of effect does not refer to the likelihood of committing the act, but to the likelihood of harm once the act has occurred. Two possible harms should be considered in relation to auditing. One is harm to the financial statement users affected by the provision of an incorrect audit opinion (Bazerman et al., 2002). If an incorrect audit opinion is issued, financial statement users may be misled to believe in the reliability of incorrect financial information and suffer losses due to inappropriate investments. An RAQ act's probability of effect is the likelihood that an incorrect audit opinion will be issued due to the RAQ act. We expect the probability of effect to differ between RAQ acts, with a high level of perceived moral intensity for false sign-off and lower levels for at least some of the other acts (cf. Herrbach, 2001). We therefore propose the following hypothesis:

H3 The perceived probability of effect on financial statement users varies across RAQ acts.

Although the main harm is incurred by the financial statement users and although auditors' rules are primarily designed to protect investors, Coram et al. (2008) argued that auditors may also be subject to harm from incorrect audit opinions. There are risks of litigation, disciplinary action, and damaged reputation. Auditors also risk punishment for committing an RAQ act, even if it does not cause an incorrect audit opinion. In that case, auditors may find themselves cast in a bad light in the audit firm. Although the detection risk was considered small in previous studies (Pierce and Sweeney, 2005, 2006), there is reason to believe that this risk still exists. Auditors who commit false sign-off tend to be mostly concerned with the risk of getting caught (Rhode, 1978). We expect that some RAQ acts are more likely to be detected by superiors or peers, and we state this expected variation as a hypothesis:

H4 The perceived probability of effect on auditors varies across RAQ acts.

\subsection{The relationship between moral intensity and auditor behaviour}

The rationale for examining the relationship between the perceived moral intensities of individual RAQ acts and their likelihood of being committed follows immediately from Jones' (1991) model. Jones extended Rest's (1986) four-stage model of ethical 
decision-making, in which moral intensity dimensions influence four stages of ethical decision-making: moral recognition, moral judgment, moral intention, and moral behaviour. Previous research has tested the model on auditors' decision-making processes with experiments using ethical vignettes and questionnaires (Cohen and Bennie, 2006; Leitsch, 2006; Sweeney and Costello, 2009).

According to Rest's (1986) model, a person must proceed through all four stages before reaching a decision regarding an ethical issue; the present study concerns only the last stage. Studies have found significant relationships between social consensus and moral intentions (Harrington, 1997) and between the magnitude of consequences and intentions to act ethically (Chia and Mee, 2000; Flannery and May, 2000; Cohen et al., 2001). Leitsch (2006) and Sweeney and Costello (2009) found support for the hypothesis that perceived moral intensity affects intentions to act ethically in other areas of accounting. Based on these studies and on recent findings of Sweeney et al. (2013), we suggest a negative relationship between the moral intensity of an individual RAQ act and its likelihood of being committed:

H5 The increasing moral intensity of an RAQ act is associated with a decreasing likelihood of an auditor's committing it.

\section{Method}

\subsection{Sample and data collection}

In total, 800 questionnaires were distributed to audit managers and partners using automatic survey software (Evasys). The software automatically delivered the questionnaire to the respondents and automatically tracked respondents and non-respondents, so it was possible to remind only non-respondents. The software provided access to the questionnaire via a link in an e-mail that each respondent in the sample received. Once the questionnaire was completed by a respondent, his or her responses were filed in a database that could be exported in Excel or SPSS format.

The selected auditors were all members of FAR, i.e., the auditing association in Sweden. Study participation was voluntary and respondents were assured that the information would be used solely for scientific purposes. The questionnaire was pilot tested with the help of two authorised auditors before its distribution. The pilot tests led to some minor changes in the questionnaire that improved comprehension. The questionnaire took about ten to fifteen minutes to complete and was distributed by e-mail. One hundred thirty-six responses were collected, and the response rate of $17 \%$ was achieved after three reminders generated by the e-mail survey software over three weeks in June 2012.

The possibility of bias in the data was dealt with as follows. Non-respondents' answers were assumed to be represented by late respondents' answers (cf. Larson and Catton, 1959; Armstrong and Overton, 1977), and any difference between late and early respondents' answers was treated as a measure of non-response bias. Mann-Whitney U tests were computed to ensure that late respondents did not answer the questions differently from early respondents. Late respondents were defined as the 30 respondents who were the last to submit their questionnaires, that is, after several reminders, while early respondents were the first 30 respondents. Results for late 
respondents were statistically indistinguishable from those for early respondents. More specifically, we tested whether there were any significant differences between early and late respondents in the four moral intensity items and all seven RAQ acts, 28 items in total. The most significant early-late difference in moral intensity was for the probability of effect on auditors dimension for the RAQ act failure to research a technical issue $(p=0.068)$, while the early-late differences for the other 27 items were all less significant $(p>0.271)$. This provides some assurance that there was no non-response bias in the data.

\subsection{Instrument}

A review of the TBP literature (e.g., Otley and Pierce, 1996a, 1996b; Herrbach, 2001; Pierce and Sweeney, 2006; Coram et al., 2008; Svanberg and Öhman, 2013) revealed that seven RAQ acts have been frequently examined in previous studies:

1 failure to pursue questionable items

2 not testing all items in a sample

3 failure to research a technical issue

4 accepting weak client explanations

5 false sign-off

6 superficial review of client documents

7 rejecting awkward-looking items from a sample.

We used a questionnaire to measure the moral intensity of these seven RAQ acts and the extent to which they occur in audit firms. The design of our questionnaire was similar to that of Coram et al. (2008) in the sections where we defined the RAQ acts and provided one illustrative example of each. In relation to the definitions and descriptions of the RAQ acts, we made one statement and asked three questions, one each about social consensus among auditors, magnitude of consequences for auditors, probability of effect on financial statement users, and probability of effect on auditors.

The moral intensity items were derived from Coram et al. (2008) and Singhapakdi et al. (1996). Social consensus was measured using a seven-point Likert scale indicating agreement with the statement 'Most auditors would agree that the act is wrong', with responses ranging from 1 (strongly disagree) to 7 (strongly agree). Magnitude of consequences was measured as the severity of disciplinary action using an item that asked respondents to indicate their agreement with the statement 'If the act were discovered, what level of disciplinary action would an audit assistant face?', with the responses ranging from 1 (no action) to 7 (severe action). We assessed the probability of effect on financial statement users using the question 'Could performance of the act lead to an incorrect audit opinion?', with responses ranging from 1 (definitely not) to 7 (definitely). The probability of effect on the auditor was measured by the likelihood of detecting an RAQ act and operationalised by an item asking respondents 'If an audit assistant performed the act, what is the probability that the act would be discovered by his/her superiors?', with responses ranging from 1 (definitely not) to 7 (definitely). As suggested by Coram et al. (2008), referring to an audit assistant regarding the statements 
of the magnitude of consequences for and probability of effect on the auditor is a way of reducing social desirability bias.

Singhapakdi et al. (1996) thoroughly discussed the validity of the moral intensity construct, and we examined the reliability of the total moral intensity construct for each of the RAQ acts using Cronbach's alpha (CA). For a compound scale to be considered reliable, it is often recommended that the CA coefficient be at least 0.7 (Pallant, 2001), but coefficients as low as 0.6 , or even lower for broad constructs, are viewed as acceptable (Van de Ven and Ferry, 1980). We found that the CA ranged from a lowest value of 0.611 for not testing all items to a highest value of 0.734 for rejecting awkward-looking items, with the other RAQ acts ranged in between. These values compare well with Sweeney and Costello's (2009) finding of values between 0.467 and 0.728 for the six-item moral intensity scale, and with the findings of two marketing studies (Singhapakdi et al., 1996; Singh et al., 2007), both using a four-item measure of moral intensity.

In line with Otley and Pierce (1996b), we measured the frequency of each RAQ act using a question about how frequently the auditor has committed each act. Respondents answered using a five-point Likert scale ranging from never (1) to nearly always (5) for each RAQ act. Similarly, the frequency of TBP was measured using a five-point Likert scale ranging from never (1) to nearly always (5). Finally, the instrument contained demographic questions about gender, age, experience, and type of audit firm. The Appendix shows all measures used.

We analysed the data for each measure individually (using non-parametric tests because the data were not normally distributed). The analyses presented in Tables 2-6 were intended to demonstrate whether the perceived moral intensity varied by RAQ act and to describe the moral intensity of each act. We performed a Friedman test for each measure of moral intensity to examine differences between the seven acts. If the Friedman test is significant, it means that there are some differences in moral intensity between RAQ acts, but it does not distinguish which pair or pairs of RAQ acts are involved. The analysis first used the overall moral intensity as a variable and then, one by one, each of the individual moral intensity items as variables. Our choice of method ensures that we can compare our results with those of Coram et al. (2008) and avoids violating data distribution assumptions. To examine the significance of pairwise differences between the moral intensities of RAQ acts, we performed Wilcoxon signed-rank tests (post hoc). These tests reveal the location of any significant differences revealed by the Friedman test. Moreover, we examined the relationship between moral intensity and the frequencies of RAQ acts using a parametric test, i.e., multiple linear regression analysis, because we found that the conditions for applying linear regression analysis were satisfied by our data. This is further discussed in the next section.

\section{Results}

\subsection{Descriptive statistics}

Table 1 presents the descriptive statistics for the study participants. Most of the sampled managers and partners were men, and six participants out of ten were employed by non-Big 4 firms. On average, the auditors were 48 years old and had more than 20 years of experience of auditing. 
Table 1 Demographic and descriptive statistics

\begin{tabular}{llccc}
\hline Variables & & Frequency & Mean & SD \\
\hline Male & 98 & & \\
Female & 38 & & \\
Big 4 firm & 54 & & \\
Non-Big 4 firm & 82 & & \\
Age (years) & & & 48.19 & 10.04 \\
Experience (years) & & 20.82 & 11.97 \\
Time budget pressure, TBP (1-5) & & 2.20 & 0.76 \\
Reduced audit quality acts, RAQ acts (1-5) & & 1.80 & 0.42 \\
RAQ act 1 & Failure to pursue questionable items (1-5) & & 1.68 & 0.59 \\
RAQ act 2 & Not testing all items in a sample (1-5) & 1.79 & 0.80 \\
RAQ act 3 & Failure to research a technical issue (1-5) & 1.57 & 0.68 \\
RAQ act 4 & Accepting weak client explanations (1-5) & & 2.01 & 0.65 \\
RAQ act 5 & False sign-off (1-5) & & 1.66 & 0.66 \\
RAQ act 6 & Superficial review of client documents (1-5) & & 2.21 & 0.77 \\
RAQ act 7 & Rejecting awkward-looking items from a sample & & 1.68 & 0.76 \\
& (1-5) & & \\
\hline
\end{tabular}

Note: The TBP and RAQ act frequencies refer to behaviours over one year.

The average TBP value is 2.20 , indicating that the sampled auditors to some extent feel TBP. Table 1 further presents the frequencies of RAQ acts determined by asking the respondents about their behaviours during the previous year, i.e., the frequencies refer to one year. The average RAQ act value is 1.80. Regarding the individual acts, failure to research a technical issue has the lowest mean value (1.57) and superficial review of client documents has the highest mean value (2.21). The descriptive statistics indicate that the sampled auditors do commit individual RAQ acts, despite being managers or partners. Moreover, for each of the seven RAQ acts, one or two respondents responded that they nearly always committed that act, while seven auditors responded that they had never committed any of the RAQ acts.

For comparison, Otley and Pierce (1996a), based on a questionnaire comprising items about five of the RAQ acts studied here, reported RAQ act frequencies of only marginally above two for junior auditors, using exactly the same scale as ours. Compared with the sample of Otley and Pierce (1996b), who used a five-point Likert scale identical to ours and found average scores for RAQ acts of 'close to two' for four of the acts considered here, our sample contains a total RAQ act score not statistically different from theirs $(p=0.05)$. In a recent study, Svanberg and Öhman (2013) reported an average total RAQ act value of 2.01 for managers and partners in a sample similar to the present one and using the same scale. Judging from the RAQ act scores from studies comparable to this, the present sample of auditors appears to commit RAQ acts at approximately the same rate. 
Table 2 Total moral intensity

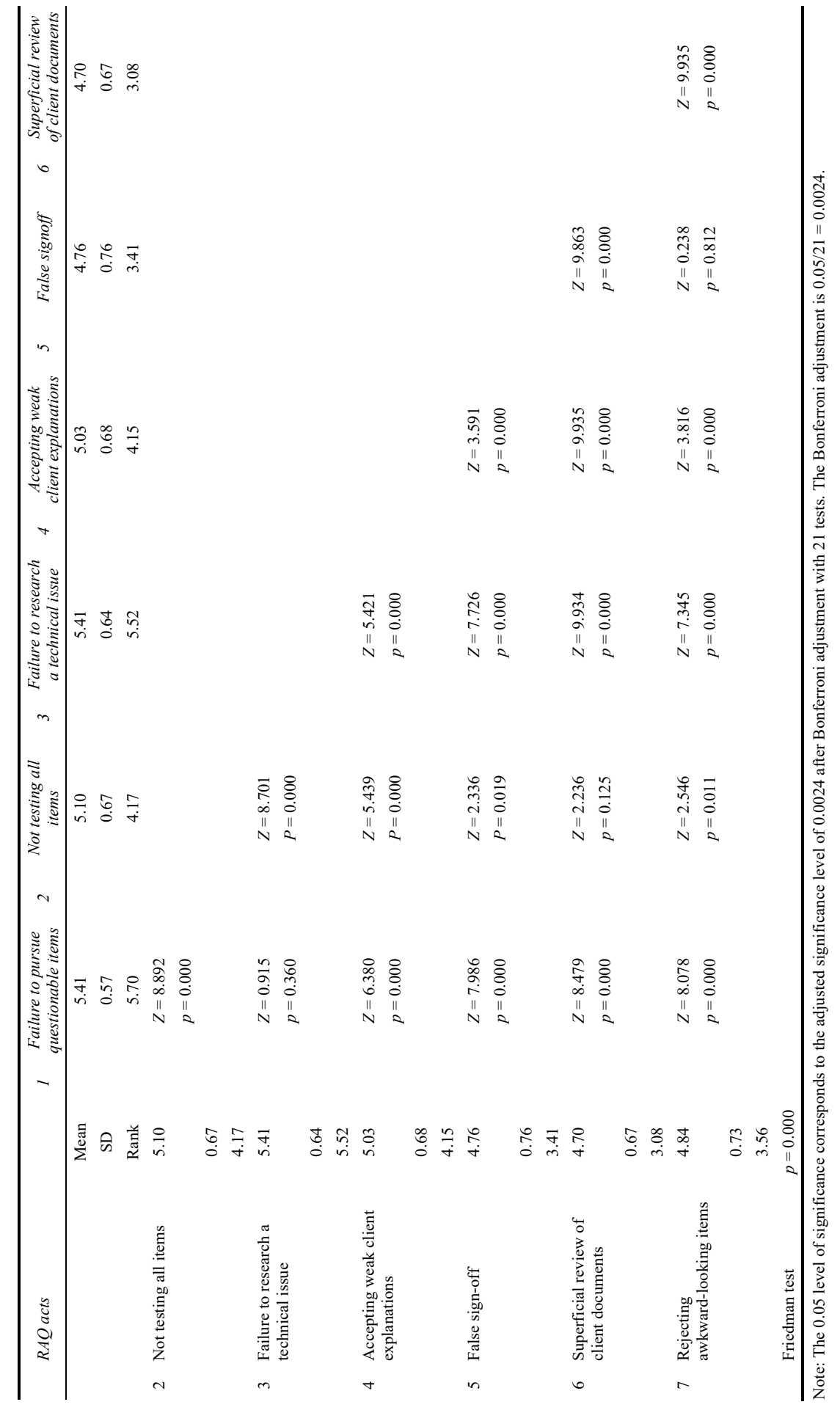




\subsection{Total moral intensity}

Table 2 presents the total moral intensity means, standard deviations, and Friedman test result (including the Wilcoxon post hoc test results) for the seven RAQ acts investigated. Total moral intensity is the arithmetic mean of the four moral intensity items. The scale's midpoint is four, so an intensity value of more than four indicates that the auditors think an act is morally wrong, a value below four that the auditors think that the act is marginally wrong, and a value of one that they do not think that the act is wrong at all. Inspection of Table 2 reveals that all RAQ acts are deemed morally questionable. However, the condemnation of the acts is not overly strong, because three of the seven acts have intensity values between four and five, and the remaining four acts just over five. The moral permissiveness regarding some of the behaviours is possibly because managers and partners believe that auditors do not commit these RAQ acts in critical areas. This form of rationalising RAQ acts has been identified by Pierce and Sweeney (2006) in interviews with auditors, and can be reconciled with the overconfidence in internal controls that may explain why RAQ acts are taking place (Cianci and Bierstaker, 2009).

When we apply the Bonferroni-adjusted 0.05 level of significance represented by the adjusted level of 0.0024 , we observe that most pairs of RAQ acts are significantly different. Apparently, there is a substantial difference in moral condemnation between not testing all items, with the lowest score (4.70), and failure to pursue questionable items and failure to research a technical issue, with the highest scores (5.41). The differences between scores in Table 2 support the claim that RAQ acts differ in perceived moral intensity.

\subsection{Social consensus among auditors}

Table 3 presents the means, standard deviations, and Friedman test result (including the Wilcoxon post hoc test results) for the social consensus variable. The experienced managers and partners in the sample believe that there is great agreement among auditors that all seven RAQ acts are wrong. Their ethical perceptions express strong repudiation, with a moral intensity of approximately 6.3 for all the acts. The lowest score is for accepting weak explanations, with a mean of 5.96, and the highest for not testing all items, with a mean of 6.76. When we apply the Bonferroni-adjusted 0.05 level of significance represented by the adjusted level of 0.0024 , we observe that social consensus regarding not testing all items is significantly stronger than that regarding failure to research a technical issue, accepting weak explanations, false sign-off, superficial review of client documents, and rejecting awkward-looking items. Although the differences between neighbours in Table 3 are frequently not significant because the values shift gradually, nine of the 21 acts differ in social consensus, lending partial support to $\mathrm{H} 1$ and the claim that moral intensity varies by RAQ act. 
Table 3 Social consensus among auditors

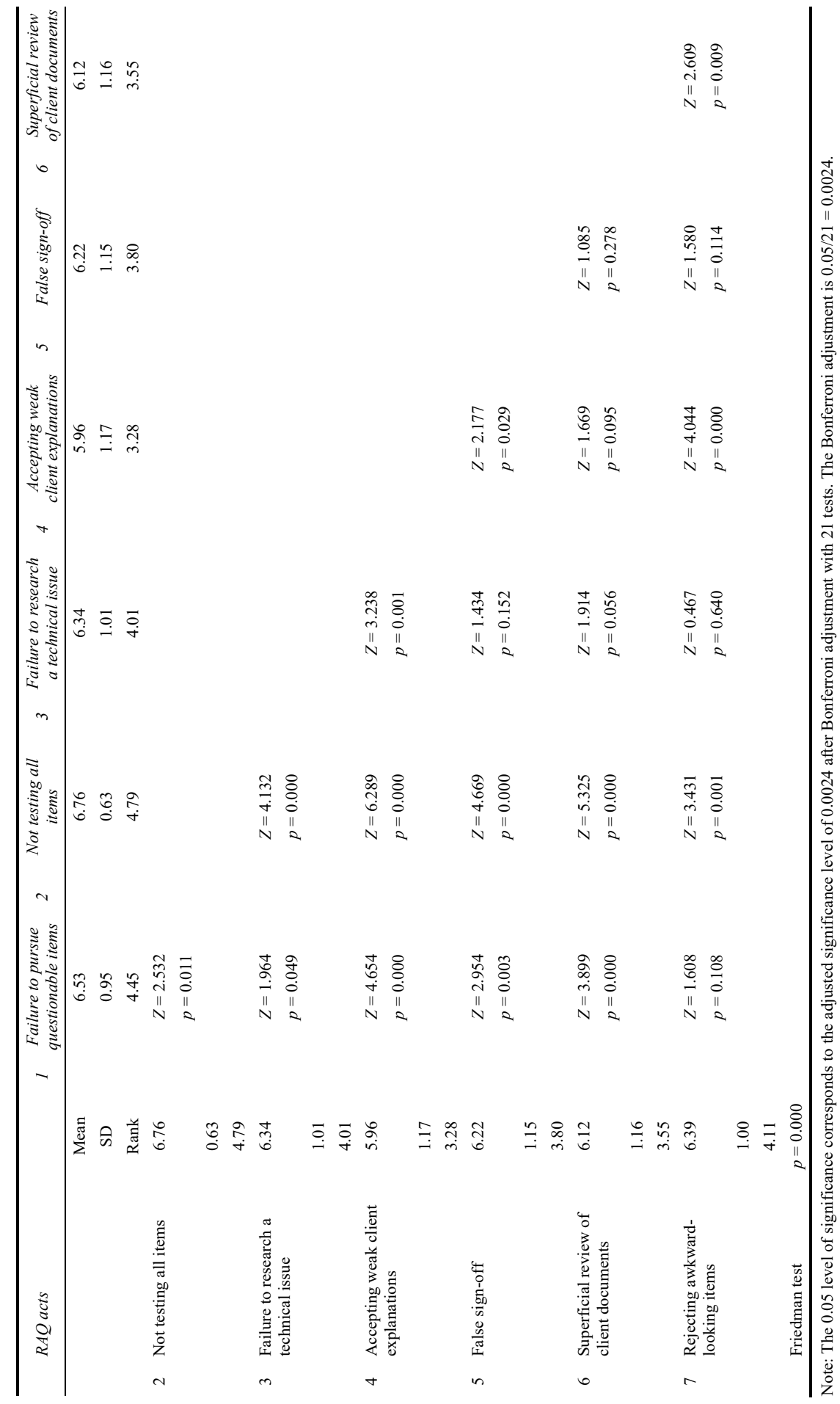


Table 4 Magnitude of consequences for auditors

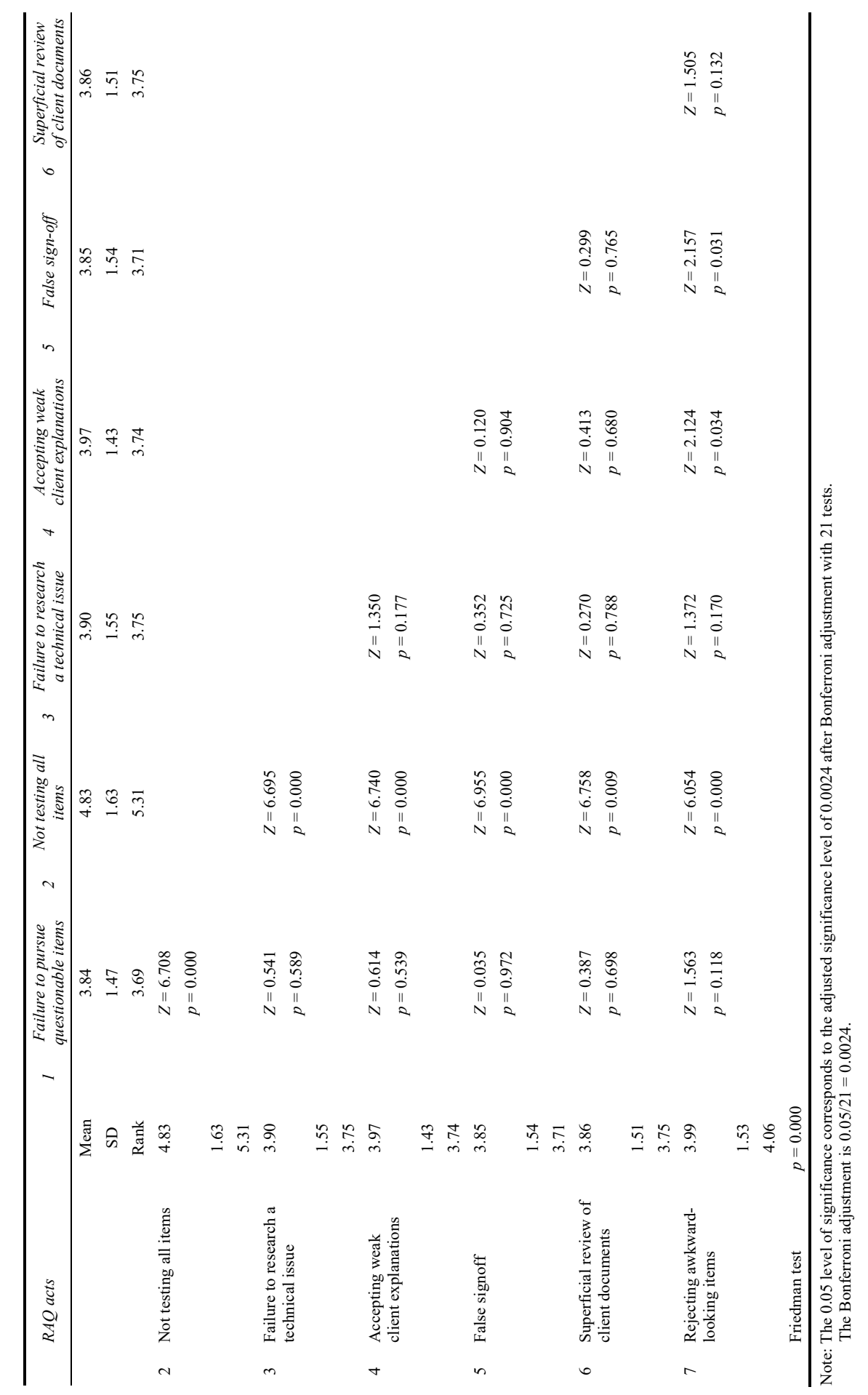


Auditors' issue contingency of reduced audit quality acts

Table 5 Probability of effect on financial statement users

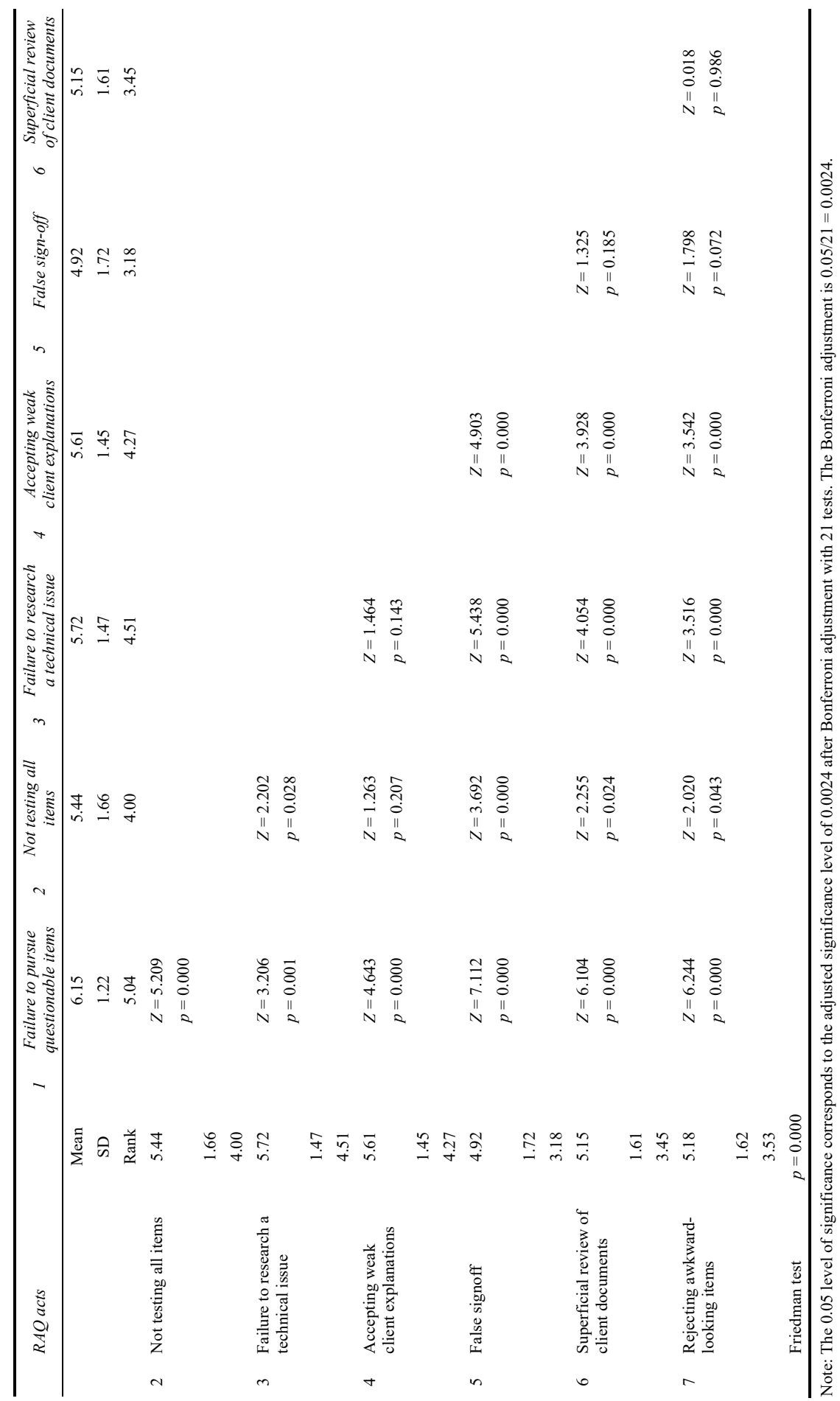




\subsection{Magnitude of consequences for auditors}

The moral intensity scores for the magnitude of consequences for auditors are presented in Table 4. The variation between RAQ acts ranges from 3.84 for failure to pursue questionable items to 4.83 for not testing all items, indicating that the managers and partners do not perceive the consequences for auditors committing RAQ acts as severe. However, the Friedman test indicates that the mean scores differ significantly between the acts. The magnitude of consequences for auditors of not testing all items is significantly higher than the mean score for all other acts except superficial review of client documents, indicating partial support for $\mathrm{H} 2$.

\subsection{Probability of effect on financial statement users}

Table 5 reports the same test results for the dimension probability of effect on financial statement users. It must be noted that the probability measured here and in the next subsection is not the actual likelihood between 0 and 1 , as referred to in probability theory, but the auditors' responses measured on a scale of 1-7. According to the scale definition, a higher score represents a higher probability, but the scores do not precisely indicate the probabilities.

There is more variation between RAQ acts for this dimension than for the social consensus and magnitude of consequences dimensions. Despite this variation, it is clear that managers and partners perceive that all RAQ acts have probable effects on financial statement users. The mean values for this moral intensity dimension extend from the lowest value (4.92) for false sign-off to the highest value (6.15) for failure to pursue questionable items, and the Friedman test indicates that there are significantly different mean scores between RAQ acts. The perceived probability of effect on financial statement users for the act failure to pursue questionable items is significantly higher than the mean score for all other acts. Other acts also differ significantly from each other, indicating that auditors perceive that the effect on financial statement users varies by RAQ act. This supports H3.

\subsection{Probability of effect on auditors}

Variations between RAQ acts in the probability of the effect on auditor dimension are presented in Table 6. Overall, it is unclear whether managers and partners believe that auditors committing RAQ acts face adverse effects. The scale midpoint is 4 , so values below this indicate relatively low moral intensities and three of the acts are below this level. The mean values for this perceived moral intensity item extend from the lowest value (3.36) for not testing all items to the highest value (5.11) for failure to pursue questionable items, and the Friedman test indicates that mean scores differ significantly among the RAQ acts. For example, the probability of effect on auditors for the act failure to pursue questionable items is significantly higher than the mean score for all other acts. The fact that 18 of the 21 Wilcoxon post hoc test results are significant for this moral intensity item emphasises support for $\mathrm{H} 4$ and the significance of variation between RAQ acts. 
Table 6 Probability of effect on auditors (detection risk)

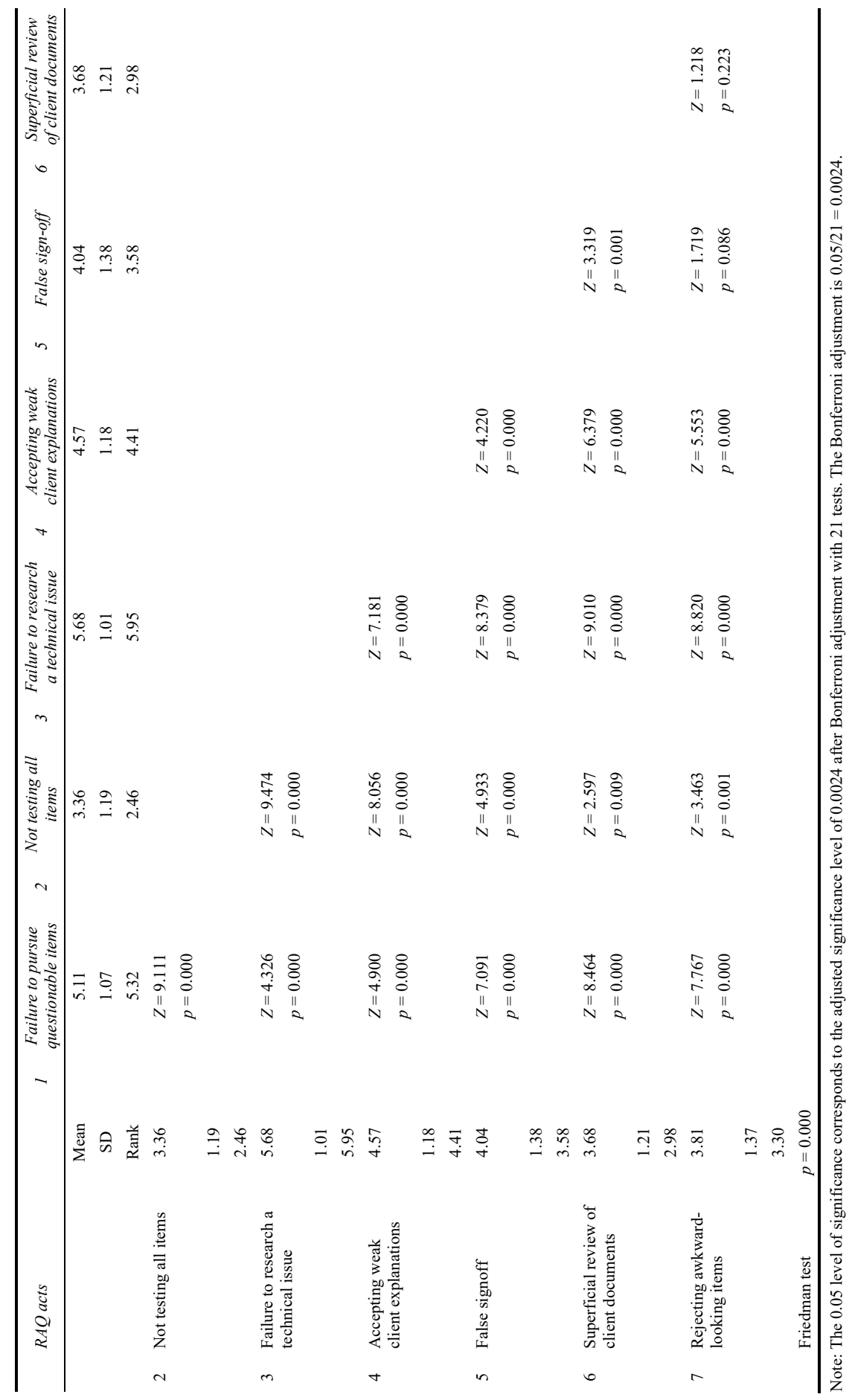


Table 7 Principal component analysis of moral intensity

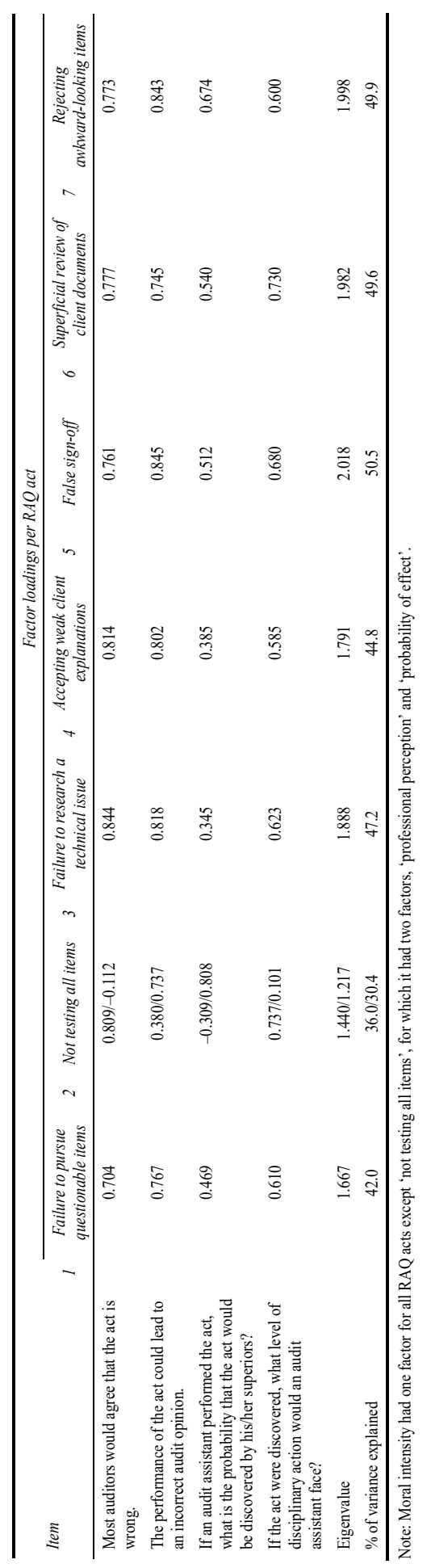




\subsection{The likelihood of committing individual RAQ acts}

We now turn to the examination of whether auditors who perceive an RAQ act as having a higher moral intensity are less likely to commit that act than are other auditors. We first present the principal component analysis of the moral intensity construct. We then describe the results of the correlation and regression analyses of the relationship between moral intensity and each of the RAQ acts. This procedure is motivated by our findings and those of Coram et al. (2008) and Sweeney et al. (2013) that different RAQ acts have different levels of moral intensity as perceived by auditors. Figure 1 illustrates how each moral intensity dimension is related to the seven RAQ acts. Although the pattern is rather similar for the acts, there are differences between, for example, RAQ act 1 (failure to pursue questionable items) and RAQ act 2 (not testing all items) regarding the (relative) effect of magnitude of consequences for auditors and probability of effect on auditors.

Figure 1 Effects of moral intensity dimensions on the seven RAQ acts (scale 1-7)

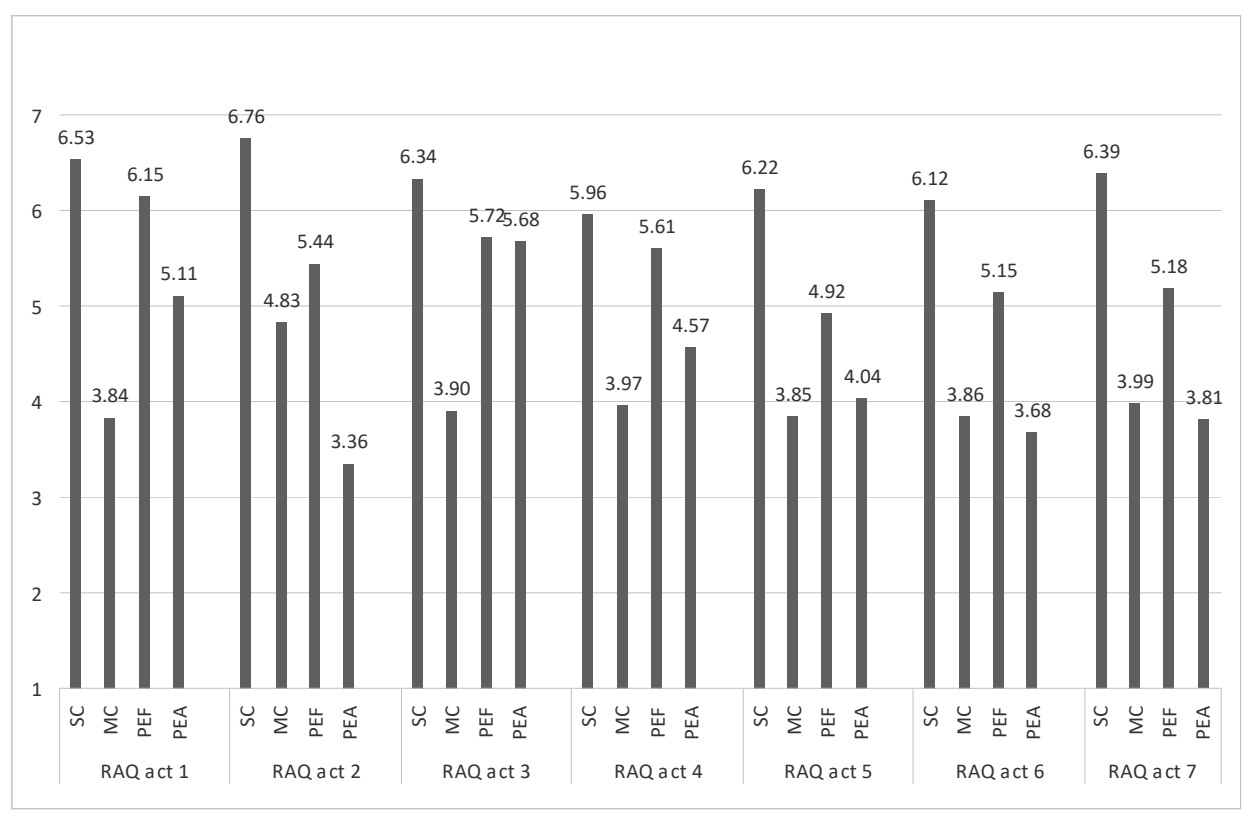

Notes: RAQ act $1=$ Failure to pursue questionable items, RAQ act $2=$ Not testing all items in a sample, RAQ act $3=$ Failure to research a technical issue, RAQ act $4=$ Accepting weak client explanations, RAQ act $5=$ False sign-off, RAQ acts $6=$ Superficial review of client documents, RAQ act $7=$ Rejecting awkward-looking items from a sample. $\mathrm{SC}=$ Social consensus among auditors, $\mathrm{MC}=$ Magnitude of consequences for auditors, PEF $=$ Probability of effect on financial statement users, PEA = Probability of effect on auditors. 
Table 8 Correlation analysis

\begin{tabular}{|c|c|c|c|c|c|}
\hline & $R A Q$ acts & $\begin{array}{c}\text { Moral } \\
\text { intensity }\end{array}$ & $T B P$ & Experience & Big 4 \\
\hline \multirow[t]{2}{*}{1} & $\begin{array}{l}\text { Failure to pursue } \\
\text { questionable items }\end{array}$ & $-0.356^{* *}$ & 0.137 & -0.043 & -0.154 \\
\hline & Moral intensity & 1 & $0.217^{*}$ & $0.280 * *$ & 0.020 \\
\hline \multirow[t]{2}{*}{2} & Not testing all items & $\begin{array}{c}-0.074 / \\
-0.154\end{array}$ & $0.175^{*}$ & -0.090 & $-0.182^{*}$ \\
\hline & Moral intensity & 1 & $-0.012 / 0.071$ & $-0.092 / 0.201 *$ & $-0.033 / 0.041$ \\
\hline \multirow[t]{2}{*}{3} & $\begin{array}{l}\text { Failure to research a } \\
\text { technical issue }\end{array}$ & -0.138 & 0.032 & -0.064 & $-0.193 *$ \\
\hline & Moral intensity & 1 & 0.041 & $0.183^{*}$ & -0.039 \\
\hline \multirow[t]{2}{*}{4} & $\begin{array}{l}\text { Accepting weak client } \\
\text { explanations }\end{array}$ & $-0.224 * *$ & 0.118 & -0.117 & $-0.224 * *$ \\
\hline & Moral intensity & 1 & 0.116 & $0.219^{*}$ & -0.030 \\
\hline \multirow[t]{2}{*}{5} & False sign-off & -0.125 & 0.026 & 0.045 & $-0.187^{*}$ \\
\hline & Moral intensity & 1 & 0.091 & 0.108 & -0.060 \\
\hline \multirow[t]{2}{*}{6} & $\begin{array}{l}\text { Superficial review of } \\
\text { client documents }\end{array}$ & $-0.190 *$ & $0.238 * *$ & 0.054 & -0.049 \\
\hline & Moral intensity & 1 & 0.168 & $0.281 * *$ & 0.103 \\
\hline \multirow[t]{5}{*}{7} & $\begin{array}{l}\text { Rejecting } \\
\text { awkward-looking items }\end{array}$ & $-0.370^{* *}$ & $0.229 * *$ & 0.055 & -0.099 \\
\hline & Moral intensity & 1 & 0.071 & $0.193^{*}$ & 0.005 \\
\hline & TBP & & 1 & -0.076 & $-0.457 * *$ \\
\hline & Experience & & & 1 & $-0.195^{*}$ \\
\hline & Big 4 & & & & 1 \\
\hline
\end{tabular}

Notes: * indicates that coefficients are significant at the 0.05 level; ** indicates that coefficients are significant at the 0.01 level. 'TBP' is the perceived auditor time budget pressure on a scale from 1 to 5. 'Experience' is the number of years the auditor has worked as an auditor. 'Big 4' is a dichotomous variable that is 1 if the audit firm is one of the Big 4 and 0 otherwise.

Moral intensity may have several dimensions, as suggested by Jones (1991) and later confirmed by Singhapakdi et al. (1996) and Sweeney and Costello (2009). However, Valentine and Silver (2001) found that moral intensity was unidimensional. A principal component analysis was conducted before the regression analysis because the four moral intensity items were highly correlated. A separate principal component analysis was conducted for each RAQ act. To ensure that the sample consisted only of auditors who conducted auditing or fieldwork, we partitioned the data by excluding auditors who reported that they had not committed RAQ acts at all during the one-year study period. Thus, the seven auditors who responded that they never committed any of the acts were omitted from the further testing of H5. This method was used by Svanberg and Öhman (2013) as a way of excluding auditors who may not conduct actual fieldwork.

The results of the principal component analysis with varimax rotation are presented in Table 7. This analysis revealed one factor with an eigenvalue greater than 1 for all RAQ acts except not testing all items, which had two factors with eigenvalues greater than 1. 
This result corresponds to those of Sweeney and Costello (2009), who found a two-dimensional structure, and of Valentine and Silver (2001), who found a unidimensional structure, both studies using a six-item measure of moral intensity. Our use of the four-item measure, adding one item to the original six but omitting three, makes it unlikely that we would find that moral intensity has more than two dimensions. The obtained one-factor structures explained $42.0-50.5 \%$ of the variance, while the two-factor structure explained $66.4 \%$ of the variance. The two-factor solution for not testing all items had one factor capturing social consensus among auditors and the magnitude of consequences for the auditor, labelled professional perception, and another factor capturing the probability of effect on financial statement users and the probability of effect on auditors, labelled probability of effect.

Spearman correlations were computed to avoid any problems with non-normal sample distributions, for example, in the univariate analyses of the hypothesised relationships. The correlations are presented in Table 8 . The moral intensity of the act not testing all items has two values due to the previously mentioned two-factor solution. The univariate analysis provides preliminary support for H5 for four of the seven RAQ acts. The acts failure to pursue questionable items, accepting weak explanations, superficial review of client documents, and rejecting awkward-looking items are all negatively correlated with moral intensity $(p<0.05)$, indicating that higher moral intensity is associated with less frequent RAQ acts.

A multiple regression analysis was performed for each RAQ act, and the results are presented in Table 9. While all previous tests were non-parametric, as a precaution due to the non-normal data distributions, we here adopt linear regression, which is a parametric test, because the conditions for regression analysis are satisfied. The distributions of the variables are not normal, but the condition of normality applies to the residuals, which in this case display only small deviations from normality. It was ensured that the residuals had a normal distribution by using the Shapiro-Wilk test and by visually examining the diagrams, all evidencing approximately normal distributions. The correlations between the independent variables in our model were low, indicating no sign of multicollinearity.

We examined H5 separately for each of the seven RAQ acts and found a relationship between moral intensity and the frequency of an RAQ act for three of the seven acts. The first of these acts (RAQ act 1) is failure to pursue questionable items. The regression is significant ( $p=0.000$ ) with an $R^{2}$ value of 0.201 , and the perceived moral intensity of this act has a significantly negative impact on its frequency $(p=0.000)$. Table 9 also indicates that Big 4 auditors engage less frequently in this act than do non-big 4 auditors. For RAQ act 4 (accepting weak client explanations), the regression is significant $(p<0.01)$, the adjusted $R^{2}$ is 0.152 , and the coefficient for moral intensity is negative and significant $(p<0.05)$. There is also a positive relationship between the frequency of the act and TBP $(p=0.01)$, and a negative relationship between the frequency of the act and audit firm affiliation $(p<0.01)$. Finally, the frequency of RAQ act 7 (rejecting awkward-looking items) is negatively related to moral intensity, as indicated by the significant coefficient $(p<0.01)$, and follows the same pattern as do the two previous acts. The regression is significant $(p<0.01)$ with an explanatory power of $R^{2}=0.168$. The relationship between the frequency of the act and TBP is significant and positive $(p<0.01)$. 
Table 9 Multiple regressions for each RAQ act

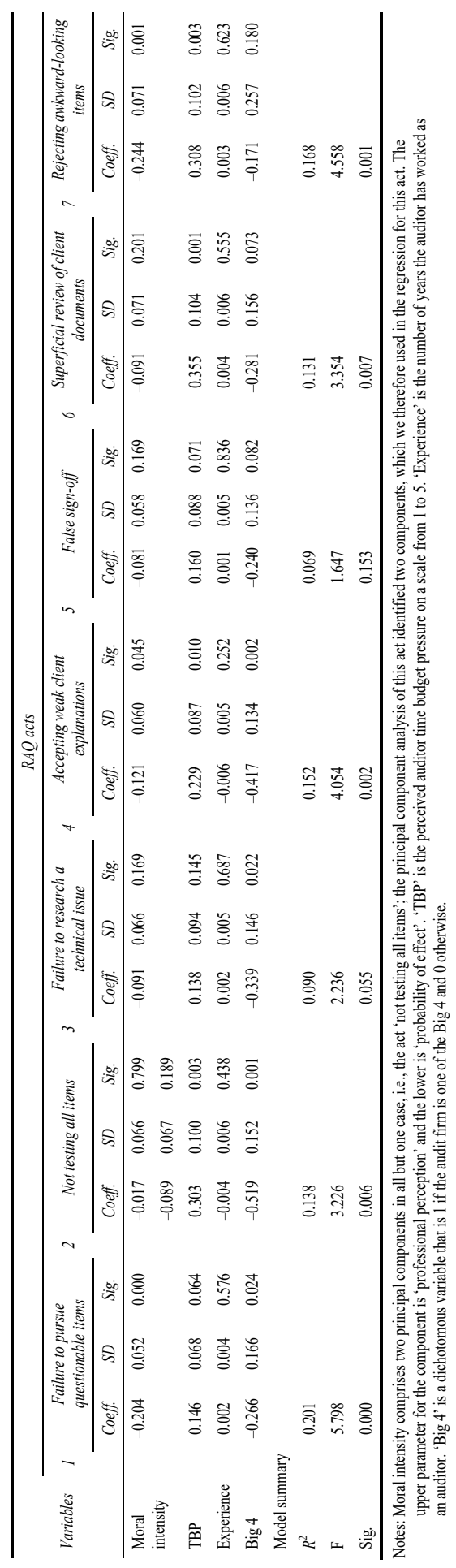


The regression coefficients for moral intensity are non-significant for the other four RAQ acts. Regarding the acts failure to research a technical issue (RAQ act 3) and false sign-off (RAQ act 5), we find no significant relationship with moral intensity. For superficial review of client documents (RAQ act 6), we find no significant relationship with moral intensity, although the regression as a whole is significant $(p<0.01)$ and the coefficient for TBP is positive and significant $(p<0.01)$, which indicates that auditors who find time budgets more attainable tend to commit the act less frequently. The act not testing all items (RAQ act 2) was examined using the two-component structure found in the principal component analysis. None of the regression coefficients for these principal components was significant. However, the regression equation is still significant $(p<0.01)$ and TBP positively affects the frequency of this act $(p<0.01)$. The findings also indicate that auditors from Big 4 firms engage less frequently in this RAQ act than do their peers from non-Big 4 firms.

In summary, we find partial support for H5. For four of the seven RAQ acts, moral intensity has no significant impact on the likelihood of committing the act. Still, the frequencies of RAQ acts are predicted by their perceived moral intensity in the case of three acts, providing some indication that moral judgment does prevent auditors from committing such acts.

\section{Discussion}

The present findings contribute to the literature as follows. First, previous studies using methodologically and theoretically diverse approaches have presented conflicting evidence regarding auditors' moral assessments of RAQ acts. Two previous studies have found that senior auditors do not perceive RAQ acts as particularly serious in their effects on auditors and audit firms (Pierce and Sweeney, 2005, 2006), while another study found that junior auditors regard RAQ acts as having serious moral implications, though very little potential risk and damage for the perpetrating auditor is perceived (Coram et al., 2008). The present study provides additional empirical evidence regarding auditors' moral intensity perceptions of RAQ acts and explores whether high-ranking auditors perceive a lack of risk and damage for themselves.

Ethical perceptions on the part of audit staff should be a tool for reducing the frequency of RAQ acts, but the views reported by Pierce and Sweeney $(2005,2006)$ suggest that auditors' moral stances may not deter them from committing RAQ acts. However, these two studies have a limited empirical basis, were based on interviews, and do not use Jones' (1991) framework, so only uncertain conclusions (i.e., no statistical inferences) about auditors' moral perceptions of RAQ acts can be drawn from these otherwise comprehensive studies. Considering the contrasting results of Coram et al. (2008), there seems to be uncertainty regarding auditors' moral views of RAQ acts. Our main result, judging from the total moral intensity score, is that managers and partners involved in fieldwork consider RAQ acts serious offences, in line with what Coram et al. (2008) reported for junior auditors. Our results differ from some of those obtained by Pierce and Sweeney $(2005,2006)$, who found that audit partners perceive RAQ acts as having few consequences for the audit firm and the wider community. We examined the probability of effect on financial statement users and found that managers and partners 
perceive a substantial probability of such effects for all seven acts investigated. The social consensus among auditors that these acts are wrong is also strong.

Second, most research into the causes of RAQ acts treats the acts as uniform phenomena, computing a composite variable combining the individual RAQ acts. This treatment may be an oversimplification if some of the acts have higher moral intensity than do others. Coram et al. (2008) found that low-ranking auditors perceived significant differences in moral intensity between various acts, and Sweeney et al. (2013) reported a similar pattern for inexperienced auditors. Our study examined 136 managers and partners, and offers complementary evidence regarding the issue contingency of RAQ acts. We found that the perceived moral intensity of RAQ acts differs on all four examined dimensions of moral intensity, at least partly supporting hypotheses $\mathrm{H} 1-\mathrm{H} 4$. The results suggest that methods to prevent RAQ acts could have differing effects across the acts. RAQ acts with high moral intensity are likely more sensitive to improvements in ethical culture (Treviño et al., 1998; Kaptein, 2008, 2011) than are acts with less moral intensity. In other words, the impact of a leader's ethical role modelling and the rewarding of ethical behaviour in audit firms may be more effective in the case of the RAQ acts with the highest moral intensities.

Although the main effect (issue contingency) is similar between the studies, we found that experienced Swedish managers and partners perceive the moral intensity of RAQ acts differently from the junior auditors in the Australian study. While Coram et al. (2008) found that false sign-off was the most serious act on the social consensus among auditors and magnitude of consequences for auditors dimensions, we find that false sign-off is ranked 6 out of 7 on the total moral intensity scale. Although country differences may explain some of these differences, another possibility is that the lack of communication about RAQ acts in audit firms may lead to quite disparate perspectives among high- and low-ranking auditors. Previous research indicates that discussing RAQ acts is more or less taboo in audit firms (McNair, 1991; Pierce and Sweeney, 2005, 2006), with the effect that it may be more problematic to speak of these acts than to commit them. Furthermore, RAQ acts may be perceived differently by different ranks of auditors because managers and partners normally do not have to rationalise their behaviour ex post to the same extent as do junior auditors. This reasoning is in line with suggestions of Willett and Page (1996) and Pierce and Sweeney (2005) that partners have a greater tendency than do junior or senior auditors to underestimate the frequency of potentially damaging RAQ acts such as premature sign-off.

Third, we found partial support for H5 about the relationship between managers' and partners' perceptions of moral intensity and their likelihood of committing RAQ acts. This is one of the few pieces of direct intra-subject evidence that auditors' moral intensity perceptions actually seem to affect the likelihood of committing RAQ acts. In addition to Sweeney et al.'s (2013) empirical evidence of a negative relationship between inexperienced auditors' perceptions of ethical intensity and their intentions to engage in three different acts, we found a negative relationship between moral intensity and self-reports of committing three of the seven studied RAQ acts. Our evidence targets actual behaviour rather than the intention to act, and in that sense offers more conclusive evidence of the impact of moral intensity on the likelihood of committing RAQ acts. The psychological literature claims that intention to act differs from real-life action because of hypothetical bias (Blumer, 1955; Campbell, 1963).

The lack of impact for the other four acts is a potential concern, because this suggests that the managers and partners in this sample do not seem to be deterred from taking 
actions in their fieldwork that are perceived as unethical. This is particularly concerning because managers and partners act as role models to low-ranking auditors. Disregarding the moral intensity of some RAQ acts may set bad examples for the inexperienced auditors they are supposed to lead, and is one possible explanation of why junior auditors commit RAQ acts even though they perceive them as morally questionable.

Fourth, we found that the average scores for magnitude of consequences for auditors and probability of effect on auditors are distinctly lower than the average scores for social consensus among auditors and probability of effect on financial statement users. In other words, managers and partners seem convinced that RAQ acts are less likely to have harmful effects on auditors than on financial statement users. While the latter group is regarded as highly likely to suffer adverse effects, audit firm management and partners obviously think that the effects on the auditors themselves are both less likely and not strikingly serious. The limited consequences for the auditors in terms of the probability of effect (detection risk) and the magnitude of consequences are supported by Pierce and Sweeney $(2005,2006)$. The understanding that the perceived costs and risks are mainly on the financial statement users' side is also confirmed by Coram et al.'s (2008) study of junior auditors. Our study, taken together with Coram et al.'s (2008), indicates that this perception exists at all levels of audit firms. It is not simply the wishful thinking of stressed junior auditors but indeed a view shared by audit firm leaders. This observation helps explain the partial support for H5. Hence, more work needs to be done in developing an ethical imperative (Shearer, 2002) that challenges the status quo in audit firms. In line with DiGabriele (2016), we encourage educational efforts regarding the major challenges of audit work. Our results also suggest that perceiving RAQ acts as grave breaches of auditors' moral obligations is an insufficient safeguard against committing the acts.

It must be emphasised that it is far from certain that the relationships are similar for high- and low-ranking auditors, which is also one of the motives of the present study. Cohen and Bennie (2006) found that the use of perceived moral intensity as a basis for decision-making in auditing is a learned skill, and there is reason to suspect that experienced auditors are better at this than are inexperienced junior auditors. Experienced experts use more efficient reasoning and inference patterns than do inexperienced professionals (Gaa, 1995). Generalising our results to audit staff may be hazardous for this reason.

The results should also be interpreted cautiously due to the low response rate and the fact that Jones' (1991) moral intensity scale uses single-item measures of the individual moral intensity dimensions. The use of single-item measures of dimensions makes the construct less reliable than it would be if it had included several items measuring each moral intensity dimension. Despite this weakness, Jones' (1991) scale has been frequently adopted in a number of research areas, including accounting, and we found that the compound measure of the total moral intensity of RAQ acts displayed satisfactory internal reliability. The relatively low perceived seriousness of false sign-off found in the present study, compared with Herrbach's (2001) arguments and the studies of Coram et al. (2008) and Sweeney et al. (2013), may be acknowledged as a potential limitation. At the least, it highlights that responses may be sensitive to the examples cited in questionnaires, a possibility that merits further research. The development of research instruments and measures related to further studies of ethical issues in the audit context is also suggested. Related to this, seven auditors were omitted from the testing of the moral 
intensity of an RAQ act and the likelihood of committing it because they reported that they had not committed any acts in the previous year. This suggests that the use of control questions, for example, concerning whether the sampled auditors had conducted actual fieldwork in the previous year, could well be useful.

\section{References}

Alderman, C.W. and Deitrick, J.W. (1982) 'Auditors' perceptions of time budget pressures and premature sign-offs: a replication and extension', Auditing: a Journal of Practice and Theory, Vol. 1, No. 2, pp.54-68.

Armstrong, J.S. and Overton, T.S. (1977) 'Estimating non-response bias in mail surveys', Journal of Marketing Research, Vol. 14, No. 3, pp.396-402.

Barnett, T. and Valentine, S. (2004) 'Issue contingencies and marketers' recognition of ethical issues, ethical judgments and behavioral intentions', Journal of Business Research, Vol. 57, No. 4, pp.338-346.

Bauer, T. (2015) 'The effects of client identity strength and professional identity salience on auditor judgments', The Accounting Review, Vol. 90, No. 1, pp.95-114.

Bazerman, M.H., Loewenstein, G. and Moore, D.A. (2002) 'Why good accountants do bad audits', Harvard Business Review, Vol. 80, No. 11, pp.97-102.

Blumer, H. (1955) 'Attitudes and the social act', Social Problems, Vol. 3, No. 2, pp.59-65.

Campbell, D.T. (1963) 'Social attitudes and other acquired behavioral dispositions', in Koch, S. (Ed.): Psychology: a Study of a Science, Vol. 6, pp.94-172, McGraw-Hill, New York.

Carlson, D.S., Kacmar, K.M. and Wadsworth, L.L. (2002) 'The impact of moral intensity dimensions on ethical decision making: assessing the relevance of orientation', Journal of Managerial Issues, Vol. 14, No. 1, pp.15-30.

Chia, A. and Mee, L.S. (2000) 'The effects of issue characteristics on the recognition of moral issues', Journal of Business Ethics, Vol. 27, No. 3, pp.255-269.

Cianci, A.M. and Bierstaker, J. (2009) 'Auditors' efficiency motivated evaluation', Advances in Accounting, incorporating Advances in International Accounting, Vol. 25, No. 1, pp.20-27.

Cohen, J.R. and Bennie, N.M. (2006) 'The applicability of a contingent factors model to accounting ethics research', Journal of Business Ethics, Vol. 68, No. 1, pp.1-18.

Cohen, J.R., Pant, L.W. and Sharp, D.J. (2001) 'An examination of differences in ethical decision-making between Canadian business students and accounting professionals', Journal of Business Ethics, Vol. 30, No. 4, pp.319-336.

Cooper, C.L., Dewe, P.J. and O'Driscoll, M.P. (2001) Organizational Stress: a Review and Critique of Theory, Research, and Applications, Sage Publications, Thousand Oaks, CA.

Coram, P., Glavovic, A., Ng, J. and Woodliff, D. (2008) 'The moral intensity of reduced audit quality acts', Auditing: a Journal of Practice and Theory, Vol. 27, No. 1, pp.127-149.

Coram, P., Ng, J. and Woodliff, D. (2004) 'The effect of risk of misstatement on the propensity to commit reduced audit quality acts under time budget pressure', Auditing: a Journal of Practice and Theory, Vol. 23, No. 2, pp.159-167.

DiGabriele, J.A. (2016) 'The expectation differences among stakeholders in the financial valuation fitness of auditors', Journal of Applied Accounting Research, Vol. 17, No. 1, pp.43-60.

Donnelly, D.P., Quirin, J.J. and O'Bryan, D. (2003) 'Auditor acceptance of dysfunctional audit behavior: an explanatory model using auditors' personal characteristics', Behavioral Research in Accounting, Vol. 15, No. 1, pp.87-110.

Flannery, B.L. and May, D.R. (2000) 'Environmental ethical decision-making in the U.S. metal fishing industry', Academy of Management Journal, Vol. 43, No. 4, pp.642-662.

Gaa, J.C. (1995) 'Moral judgment and moral cognition: a comment', Research on Accounting Ethics, Vol. 1, pp.253-265. 
Harrington, S.J. (1997) 'A test of a person-issue contingent model of ethical decision-making in organizations', Journal of Business Ethics, Vol. 16, No. 4, pp.363-375.

Herrbach, O. (2001) 'Audit quality, auditor behavior and the psychological contract', European Accounting Review, Vol. 10, No. 4, pp.787-802.

Jones, T.M. (1991) 'Ethical decision-making by individuals in organizations: an issue-contingent model', Academy of Management Review, Vol. 16, No. 2, pp.366-395.

Kaplan, S.E. (1995) 'An examination of auditors' reporting intentions upon discovery of procedures prematurely signed-off', Auditing: a Journal of Practice and Theory, Vol. 14, No. 2, pp.90-104.

Kaptein, M. (2008) 'Developing and testing a measure for the ethical culture of organizations: the corporate ethical virtues model', Journal of Organizational Behavior, Vol. 29, No. 7, pp.923-947.

Kaptein, M. (2011) 'Understanding unethical behavior by unraveling ethical culture', Human Relations, Vol. 64, No. 6, pp.843-869.

Kelley, T. and Margheim, L. (1990) 'The impact of time budget pressure, personality and leadership variables on dysfunctional behaviour', Auditing: a Journal of Practice and Theory, Vol. 9, No. 2, pp.21-41.

Larson, R. and Catton Jr., W. (1959) 'Can the mail-back bias contribute to a study's validity?', American Sociological Review, Vol. 24, No. 2, pp.243-245.

Lee, B. (2002) 'Professional socialization, commercial pressures and junior staff's time-pressured irregular auditing: a contextual interpretation', British Accounting Review, Vol. 34, No. 4, pp.315-333.

Leitsch, D.L. (2006) 'Using dimensions of moral intensity to predict ethical decision-making in accounting', Accounting Education: an International Journal, Vol. 15, No. 2, pp.135-149.

Malone, C.F. and Roberts, R.W. (1996) 'Factors associated with the incidence of reduced audit quality behaviors', Auditing: a Journal of Practice and Theory, Vol. 15, No. 2, pp.49-64.

Margheim, L. and Pany, K. (1986) 'Quality control, premature sign-off and underreporting of time: some empirical findings', Auditing: a Journal of Practice and Theory, Vol. 5, No. 2, pp.50-63.

McMahon, J.M. and Harvey, R.J. (2007) 'The effect of moral intensity on ethical judgment', Journal of Business Ethics, Vol. 72, No. 4, pp.335-357.

McNair, C.J. (1991) 'Proper compromises: the management control dilemma in public accounting and its impact on auditor behaviour', Accounting, Organizations and Society, Vol. 16, No. 7, pp.635-653.

Otley, D.T. and Pierce, B.J. (1996a) 'Audit time budget pressure: consequences and antecedents', Accounting, Auditing and Accountability Journal, Vol. 9, No. 1, pp.31-58.

Otley, D.T. and Pierce, B.J. (1996b) 'The operation of control systems in large accounting firms', Auditing: a Journal of Practice and Theory, Vol. 15, No. 2, pp.65-84.

Pallant, J. (2001) SPSS Survival Manual: a Step-by-Step Guide to Data Analysis using SPSS for Windows, Open University Press, Buckingham, UK.

Pierce, B. and Sweeney, B. (2004) 'Cost-quality conflict in accounting firms: an empirical investigation', European Accounting Review, Vol. 13, No. 1, pp.415-441.

Pierce, B. and Sweeney, B. (2005) 'Management control in accounting firms: partners' perspectives', Management Accounting Research, Vol. 16, No. 3, pp.340-370.

Pierce, B. and Sweeney, B. (2006) 'Perceived adverse consequences of quality threatening behaviour in audit firms', International Journal of Auditing, Vol. 10, No. 1, pp.19-39.

Rest, J.R. (1986) Moral Development: Advances in Research and Theory, Praeger, New York.

Rhode, J.G. (1978) The Independent Auditor's Work Environment: a Survey, CAR Research Study No. 4, AICPA, summarized in Commission on Auditors' Responsibilities (CAR), Report, Conclusions and Recommendations, New York. 
Shaub, M.K. and Braun, R.L. (2014) 'Auditing ethics' in Hay, D., Knechel, R. and Willekens, M. (Eds.): The Routledge Companion to Auditing, pp.264-275, Routledge, Abingdon, UK.

Shearer, T. (2002) 'Ethics and accountability: from the for-itself to the for-the-other', Accounting, Organizations and Society, Vol. 27, No. 6, pp.541-573.

Singh, J.J., Vitell, S.J., Al-Khatib, J. and Clark II, I. (2007) 'The role of moral intensity and personal moral philosophies in the ethical decision making of marketers: a cross-cultural comparison of China and the United States', Journal of International Marketing, Vol. 15, No. 2, pp.86-112.

Singhapakdi, A., Vitell, S.J. and Kraft, K.L. (1996) 'Moral intensity and ethical decision-making of marketing professionals', Journal of Business Research, Vol. 36, No. 3, pp.245-255.

Svanberg, J. and Öhman, P. (2013) 'Auditors' time pressure: does ethical culture support audit quality?', Managerial Auditing Journal, Vol. 28, No. 7, pp.572-591.

Svanberg, J. and Öhman, P. (2016) 'The effects of time budget pressure, organizational professional conflict, and organizational commitment on dysfunctional auditor behavior', International Journal of Accounting, Auditing and Performance Evaluation, Vol. 12, No. 2, pp.131-150.

Sweeney, B. and Costello, F. (2009) 'Moral intensity and ethical decision-making: an empirical examination of undergraduate accounting and business students', Accounting Education: an International Journal, Vol. 18, No. 1, pp.75-97.

Sweeney, B. and Pierce, B. (2006) 'Good hours and bad hours and auditors' defence mechanisms in audit firms', Accounting, Auditing and Accountability Journal, Vol. 19, No. 6, pp.858-892.

Sweeney, B., Arnold, D. and Pierce, B. (2010) 'The impact of perceived ethical culture of the firm and demographic variables on auditors' ethical evaluation and intention to act decisions', Journal of Business Ethics, Vol. 93, No. 4, pp.531-551.

Sweeney, B., Pierce, B. and Arnold, D. (2013) 'The impact of perceived ethical intensity on audit-quality-threatening behaviours', Accounting and Business Research, Vol. 43, No. 2, pp.112-137.

Taylor, E.Z. and Curtis, M.B. (2013), 'Whistle blowing in audit firms: organizational response and power distance', Behavioral Research in Accounting, Vol. 25, No. 2, pp.21-43.

Treviño, L.K., Butterfield, K.D. and McCabe, D.L. (1998) 'The ethical context in organizations: influences on employee attitudes and behaviors', Business Ethics Quarterly, Vol. 8, No. 3, pp.447-476.

Valentine, S.L. and Silver, L. (2001) 'Assessing the dimensionality of the Singhapakdi, Vitell and Kraft measure of moral intensity', Psychological Reports, Vol. 88, No. 1, pp.291-294.

Van de Ven, A.H. and Ferry, D.L. (1980) Measuring and Assessing Organizations, Wiley, New York.

Willett, C. and Page, M. (1996) 'A survey of time budget pressure and irregular auditing practices among newly qualified UK chartered accountants', British Accounting Review, Vol. 28, No. 2 , pp.101-120.

\section{Appendix}

\section{Measures used in the study}

\section{Part 1 RAQ acts}

The following seven RAQ acts were described one at a time. For each of the RAQ acts we made statements/asked the questions regarding each moral intensity dimension as presented below Act 1 . 
Act 1 Failure to pursue questionable items

This act refers to an auditor's failure to extend the scope of examination when the auditor detects suspicious transactions.

Example: while checking a sample of transactions, the auditor observes unusually large transactions. The auditor neglects to investigate these questionable items.

\section{Moral intensity}

1 Social consensus among auditors

Most auditors would agree that the act is wrong. Scale from 1 (strongly disagree) to 7 (strongly agree). Social consensus among auditors

2 Magnitude of consequences for auditors

If the act were discovered, what level of disciplinary action would an audit assistant face? Scale from 1 (no action) to 7 (severe action).

3 Probability of effect on financial statement users

Could performance of the act lead to an incorrect audit opinion? Scale from 1 (definitely not) to 7 (definitely).

4 Probability of effect on auditors

If an audit assistant performed the act, what is the probability that the act would be discovered by his/her superiors? Scale from 1 (definitely not) to 7 (definitely).

\section{Frequency of $R A Q$ act}

During the last year, how often did you act in the described manner when carrying out an audit? Scale from never (1) to nearly always (5)

The moral intensity and the frequency of RAQ act questions were repeated for each of the RAQ acts below.

Act 2 Not testing all items in a sample

This act refers to not performing designated audit procedures for each item.

Example: the auditor tests a sample of recipients of cash received. The auditor sometimes indicates that the cash has been received without checking that it has been received.

Act 3 Failure to research a technical issue

This act refers to not checking the standards relevant to an issue, even though the auditor is unsure of the correct accounting treatment.

Example: the auditor is unsure of how a company should account for goodwill purchase consideration that comprises shares. The auditor neglects to research this issue and accepts the client's treatment. 


\section{Act 4 Accepting weak client explanations}

This act refers to accepting weak client explanations and using them as a substitute for other evidence that the auditor could expect to find.

Example: the auditor cannot find the documentation to support certain entries. The auditor asks management about the problem, who explains that the documents have been mislaid, but that they are sure the entries have been correctly recorded. The auditor accepts this explanation.

Act 5 False sign-off

This act refers to falsely signing off a required audit step, not covered by other steps, without completing the work or noting the omission of procedures.

Example: the auditor has finished vouching invoices to dispatch notes and approved sales orders. The auditor neglects to perform a separate audit step on the accuracy of pricing, and instead signs off the procedure as completed.

\section{Act 6 Superficial review of client documents}

This act refers to quickly reviewing supporting documents without paying sufficient attention to their validity and accuracy.

Example: the auditor reviews supporting documents for a sample of purchases, and makes checkmarks on audit schedules without much consideration of the content of the documents.

Act 7 Rejecting awkward-looking items from a sample

This act refers to discarding items that are complex or time consuming during the examination.

Example: the auditor avoids invoices that have many supporting documents stapled to them and ones that have many manuscript queries or annotations.

\section{Part 2 Time budget pressure}

During the last year, how often did you fail to achieve your time budgets? Scale from never (1) to nearly always (5)

\section{Part 3 Demographic information about the respondents}

Gender? Male or Female

How old are you?

How many years have you worked as an auditor?

Do you work for any of the following audit firms: Deloitte, EY, KPMG, or PwC? Yes or No 